\title{
Breaking the measurement and evaluation deadlock: A new approach and model
}

\author{
Jim Macnamara \\ University of Technology Sydney
}

\begin{abstract}
Purpose - Noting findings by Michaelson and Stacks in the US and Zerfass and colleagues in Europe that research-based measurement and evaluation of public relations and corporate communication are still not widely applied despite more than a century of discussion and intense focus since the 1970s, this paper explores the causes of this deadlock and presents an alternative approach and model to overcome identified obstacles and provide new insights to advance this important area of theory and practice.
\end{abstract}

Design/methodology/approach - This paper is informed by critical analysis of the large body of literature on measurement and evaluation, analysis of M\&E reports, and ethnographic research among senior management.

Findings - This analysis reveals that, along with long-cited barriers such as lack of budget, lack of knowledge and lack of standards, three other obstacles prevent demonstration of the value of PR and corporate communication. Based on critical analysis of literature and M\&E reports and ethnography, this paper presents a new approach and model for M\&E to help practitioners overcome these obstacles.

Research implications - This analysis and the approach and model presented address an area of concern identified in research globally, such as a 2008 Delphi study by Watson and the European Communication Monitor in 2011 and 2012. The findings provide theoretical and practical contributions to address the deadlock between normative theories of $M \& E$ and practical implementation.

Originality/value - The approach and M\&E model presented make a significant original contribution to theory and practice.

Keywords - Measurement, evaluation, PR research, evaluation models.

\section{The measurement and evaluation deadlock}

Public relations and corporate communication are caught in a deadlock in relation to measurement and evaluation. The field has accumulated and widely disseminated a substantial body of normative theories, models and 'Best Practice' advice, which advocate rigorous research-based measurement and evaluation (M\&E). However, while recognizing and acknowledging recent industry initiatives such as the Barcelona Declaration of Measurement Principles and development of international standards (Marklein and Paine, 2012), a number of studies show that Jim Grunig's cri de coeur about lack of evaluation in practice uttered in the early 1980s still echoes across the PR and corporate communication landscape today (Grunig, 1983). To paraphrase his fundamentalist metaphor, people keep on sinning and many PR people continue to not do evaluation, as is shown in the research literature reviewed. 
The paradox evident in the substantial body of research literature, theories and models on one hand, and lack of implementation on the other, and its existence over many decades, indicate that the failure of many practitioners to conduct measurement and evaluation is no longer a lag as practice catches up to research, nor a temporary problem being overcome with the passage with time. The deadlock that is evident suggests there are obstacles or barriers that have not yet been identified and which need to be addressed. While some obstacles to effective implementation of $M \& E$ have been recognized, these do not adequately explain the deadlock, as strategies to address or circumvent them have been presented, as discussed in the following. Hence, it is argued here that further research and rethinking are required to 'get to the bottom' of the measurement and evaluation dichotomy and identify a 'circuit breaker' to resolve the deadlock and establish a pathway to progress. This is a challenging undertaking, but one which must be addressed by scholars concerned about the impact of their research on practice, industry and communities.

\section{M\&E theories and models -50 plus years of literature}

An extensive body of literature on the importance of $M \& E$ and various methods for its implementation has been established and will only be summarized here, as it has been reviewed in detail in a number of analyses including Watson (2012) and Likely and Watson (2013). Measurement and evaluation have been practiced in basic forms such as media monitoring since the nineteenth century before the term public relations came into use (Lamme and Russell, 2010). For instance, Watson (2012) reported that the first press clipping agencies were established in the US and UK in the late 1800s. Focus on a research-based approach to measurement and evaluation dates back to Edward Bernays, identified in much (albeit US) PR literature as the "father of public relations" (Guth and Marsh, 2007, p. 70). Watson points out that, whereas fellow US PR pioneer Ivy Lee regarded his practice as an art, Bernays saw PR as an applied social science which should be planned using opinion research and "precisely evaluated" (2012, p. 391). Likely and Watson also note the use of opinion research by Arthur Page in the early twentieth century (2013, p. 144).

Following the work of Bernays, Page and other pioneers, published literature on the importance of research for measurement and evaluation of PR began to proliferate in the late 1950s when the second edition of Cutlip, Center and Broom's Effective Public Relations was published. After referring to the importance of public opinion research in the first edition (Cutlip and Center, 1952), their second edition in 1958 added evaluation as the fourth step in the 'PR process' after “fact-finding, planning and communicating” (Hallahan, 1993, p. 198).

Shortly after, Cutlip, Center and Broom presented their Planning, Implementation, Impact (PII) model (Cutlip et al, 1985), which has been widely disseminated and discussed since in PR textbooks and practical manuals as well as scholarly literature. Likely and Watson (2013), Watson (2012), and Watson and Noble (2014) identify a major focus on M\&E from the 1970s. Likely and Watson say a conference organized and chaired by Jim Grunig at the University of Maryland in 1977 was a "prime catalyst" for scholarly attention to M\&E, as well as a special issue of Public Relations Review on 'Measuring the effectiveness of public relations' published in the same year. Other landmark publications in the "flowering of research" that occurred in the 1970s and the early 1980s included the work of Broom and Dozier (1983) and Dozier (1984, 1985), along with Grunig's continued advocacy (Grunig, 1979, 1983) and that of some leading practitioners such as Walter Lindenmann of Ketchum $(1979,1980)$.

In a pioneering book on PR research published in the late 1980s, Pavlik (1987) compared measurement and evaluation to the Holy Grail - a view echoed by L'Etang in the twenty-first 
century when she noted that "evaluation has become and remains something of a 'holy grail' for public relations" (2008, p. 26). This was followed soon after by another landmark book on research for measurement and evaluation of PR and corporate communication, Using Research in Public Relations: Applications to Program Management by Broom and Dozier (1990). These two specialist books on research for PR, along with general PR texts such as Grunig and Hunt's (1984) seminal Managing Public Relations, meant that clear guidelines on methodology and methods for M\&E were available to academics and practitioners by 1990 .

Following the PII model, a number of other models of PR research for measurement and evaluation were published in a period of escalating development of M\&E literature during the 1990s, including the Macro Model of Evaluation (Macnamara, 1992, 1999), which evolved into the Pyramid Model of PR Research (Macnamara, 2002, 2012); the PR Effectiveness Yardstick (Lindenmann, 1993); the Short Term Model and Continuing Model of Evaluation (Watson, 1997; Watson and Noble, 2014, p. 65); and the Unified Evaluation Model (Noble and Watson, 1999; Watson and Noble, 2007, 2014). All of these models identify key stages of measurement and evaluation, such as inputs, outputs, outtakes and outcomes, and some identify specific research methods, tools and techniques for calculating and demonstrating the returns from and value of PR and corporate communication.

Industry bodies also began to produce position statements, manuals and guides on M\&E. Noteworthy examples included the International Public Relations Association (IPRA) Gold Paper on Evaluation (IPRA, 1994) and the Planning Research, Evaluation (PRE) process developed by the UK Institute for Public Relations (now the Chartered Institute for Public Relations) in 2001 as part of its 'Public Relations Research and Evaluation Toolkit' (Fairchild, 2001; Watson and Noble, 2014, p. 63). Updated since and renamed the 'Research, Planning and Measurement Toolkit' in 2010, this identifies five stages in the practice of PR as (1) conduct research to audit "where we are now"; (2) set objectives; (3) develop a strategy and plan; (4) conduct ongoing measurement; and (5) evaluate results (CIPR, 2011). The Public Relations Society of America (PRSA) has published a range of resources for M\&E over the past two decades, most recently reflecting the Barcelona Principles and emerging standards for M\&E (see PRSA, 2014). Watson and Noble also note a number of other practitioner-developed models and tools including dashboards and scorecards (2014, p. 72).

The 2000s saw an ever-growing body of epistemological and methodological contributions in relation to M\&E. For example, in interviews with CEOs conducted as part of the Excellence study, L. Grunig, J. Grunig and Dozier (2002) used a compensating variation approach, which was discussed in the first Excellence study book by Ehling (1992). Compensating variation is based on a simple idea: ask stakeholders how much they would be willing to pay for a non-monetary benefit. For instance, in the case of PR and corporate communication, practitioners can ask senior managers how much they believe a good reputation or positive relationships with key publics are worth to the organization. In the Excellence study, the researchers found that most CEOs readily agreed that PR contributed value to their organization and most could estimate that value in numerical terms - albeit not in financial terms typical of Return on Investment (ROI) methods. CEOs interviewed estimated the average return on investment from PR at 186 per cent and up to 225 per cent under conditions of PR excellence as identified in the Excellence study. Even the least excellent PR departments were estimated to produce a 140 per cent return on investment by their CEOs (p. 109). The Excellence study researchers acknowledged that these are not "hard" precise measures, but argued that they provided "strong statistical evidence of the value of public relations" (J. Grunig, L. Grunig and Dozier, 2006, p. 37). They later concluded that "compensating variation provided the best method known to date to estimate the value of relationships cultivated by public relations” (Grunig et al., 2006, p. 35). 
A number of other related theoretical concepts also have been advanced, such as Benefit Cost Ratio (BCR) and Cost Effectiveness Analysis (CEA) developed by Likely (2012; see also Likely and Watson, 2013). BCR uses the economic concept of compensating variation discussed in Ehling (1992) and Grunig et al. (2002, pp.116-21), but takes it a step further by comparing the estimated value of results with the cost of activities. While similar to Return on Investment (ROI), it has the advantage of being applicable to non-financial benefits, as explained by Grunig et al. (2006). Yet more widely discussed methods of M\&E include market mix modelling (Weiner, 2006), communication controlling or communication performance management (Zerfass, 2010) and logic models to connect PR processes to organizational outcomes (Macnamara, 2013).

\section{M\&E implementation}

However, despite extensive discussion of and experimentation with measurement and evaluation for more than a century and intensive focus since the 1970s, a number of studies have shown that most practitioners continue to mostly use informal "seat of the pants" methods (Grunig and Hunt, 1984, p. 77; Pavlik, 1987, p. 91) and sometimes spurious methods. For example, a global study of M\&E practices in 2009 found that rudimentary counting of media clippings, subjective internal reviews, and advertising value equivalents (AVEs) were the three most used methods (Wright, Gaunt, Leggetter et al., 2009).

Gregory and Watson (2008) noted a "stasis" in M\&E and more recently Michaelson and Stacks reported that "public relations practitioners have consistently failed to achieve consensus on what the basic evaluative measures are or how to conduct the underlying research for evaluating and measuring public relations performance” (2011, p. 1). The 2012 European Communication Monitor, based on a survey of 2,200 practitioners in 42 European countries, reported that 75 per cent of European practitioners identified inability "to prove the impact of communication activities on organizational goals" as a "major barrier to further professionalization and growth” (Zerfass, Verčič, Verhoeven et al., 2012, p. 36).

The industry's struggle with measurement and evaluation continues with social media. A longitudinal study of social media use by PR and corporate communication practitioners from 2006 to 2012 by Wright and Hinson (2012) found that 54 per cent measured what external publics said about them in blogs or other social media (i.e., monitoring and content analysis), but only 26 per cent reported that they measure the impact of social media communication on the formation, change and reinforcement of attitudes, opinions and behaviour.

\section{Identified obstacles to M\&E}

A number of alleged obstacles or barriers to implementing research-based M\&E have been identified by practitioners and scholars, particularly lack of budget (i.e., cost), lack of knowledge or expertise, and lack of standards, as well as some others such as lack of employer interest, complexity, and lack of connection to organizational outcomes. Notwithstanding some validity in these claims, strategies for overcoming most have been widely discussed, as noted in the following.

\section{Lack of budget (cost)}

Despite frequent claims that practitioners cannot do M\&E because of lack of budget (Wright et al., 2009), Lindenmann (2001) pointed out that "research doesn't have to put you in the poorhouse". In a paper with that title, he listed seven suggestions for doing research in highly cost-effective ways, including omnibus surveys, self-administered mini-surveys of small 
samples, and online surveys. The Pyramid Model of PR Research (Macnamara, 2002, 2012) lists a wide range of informal and formal methods for M\&E, including a number of low-cost and even no-cost methods such as case studies, consultative groups, online feedback forums, response mechanisms and self-administered e-surveys. Furthermore, with industry studies showing steady growth in PR budgets after a temporary decline during the Global Financial Crisis - e.g., an 8 per cent average growth worldwide in 2012 (ICCO, 2013a) - lack of budget is revealed as an excuse rather than a reason for lack of M\&E.

\section{Lack of knowledge}

A number of scholars have concluded that a primary obstacle to implementation of researchbased M\&E is lack of knowledge (e.g., Cutler, 2004; Walker, 1997; Watson and Noble, 2007; White and Blamphin, 1994), also expressed as a "lack of expertise" (Baskin, Hahn, Seaman and Reines, 2010, p. 111). Cutler commented that "understanding and application of appropriate methodology is a major issue for public relations researchers" (2004, p. 372). Watson and Noble (2007) noted that practitioners largely operate as technicians, rather than as managers or strategists and need to "break the technician mould" (p. 46). Jim Grunig reaffirmed his view that lack of knowledge of research methods among practitioners is a major obstacle in a 2014 interview as part of a 'Thought leaders' in PR measurement' series, saying "the one variable that consistently explains why public relations people do what they do is their level of knowledge” (Grunig, 2014, para. 4).

In response to calls for increased knowledge of research, PR educators have focussed on research methodologies and methods in undergraduate and graduate education. Studies informing this increased emphasis include the 2006 Commission on Public Relations Education report, which recommended that undergraduate education include "research and results measurement" (VanSlyke Turk, 2006, p. 6) as well as research being a core component of graduate education (p. 7). In addition to emphasizing research in academic graduate programs focussed on preparing students for a research career, the Commission on Public Relations Education (2012) report on standards for masters degrees recommended providing "social science research and evaluation knowledge and skills" (p. 4) and incorporating "research methods" as a core curriculum component (p. 12) in professional Masters degrees.

Professional institutes and associations in number of countries also have introduced professional development short courses in research and numerous conferences, seminars and workshops open to practitioners as well as academics highlight measurement and evaluation - e.g., annual summits on measurement instigated by Katie Paine in the US and subsequently sponsored by the Institute for Public Relations (IPR) and the annual International Summit on Measurement in Europe organized by the Association for Measurement and Evaluation of Communication (AMEC). It can be argued that practitioners have had ample opportunity over the past decade or two to gain knowledge of research for M\&E.

\section{Lack of standards}

Wright et al. (2009) identified a lack of standards as a further obstacle cited by practitioners for lack of M\&E. More recently, Michaelson and Stacks (2011) reported that more than twothirds of practitioners believe a common set of standards for measurement and evaluation are necessary, and a 2013 survey of practitioners similarly reported that 66 per cent of PR professionals cited "lack of standards as the biggest problem with PR measurement" (Ragan/NASDAQ OMX, 2013). As Michaelson and Stacks noted, standards are important as they allow "comparative evaluations" over time and they ensure appropriate methods are used (2011, p. 4). 
A series of international initiatives was launched in 2011 under the auspices of the Coalition for Public Relations Research Standards established by AMEC, IPR and the Council of PR Firms (CPRF). The "march to standards" expanded in 2012 to include the Social Media Measurement Standards Conclave and involved 11 professional PR and communication organizations worldwide, as well as consultation with five media and advertising industry bodies and eight companies representing employer perspectives. While inconsistencies in definitions, terminology and methodology remain and signs of a continuing theory-practice gap continue in that the "march to standards" has included limited input from academic researchers to date (Macnamara, 2014), some significant progress has been made in developing standards.

\section{The myth of the 'silver bullet'}

A further obstacle identified by a number of researchers has been the search by practitioners for a 'silver bullet' (Gregory and White, 2008; Likely and Watson, 2013, p. 156), a single simple method of M\&E. However, this has been denounced by scholars and their colleagues - e.g., Skelley and Ziviani (2012) in the AMEC 'PR Professionals Definitive Guide to Measurement'. A vast body of academic and professional literature points to the need to apply recognized social science and interpretative research methods for $\mathrm{M} \& \mathrm{E}$.

\section{Lack of interest among employers}

A study of European providers and consumers of measurement and evaluation by Baskin et al. (2010) found some evidence to support anecdotal claims by practitioners that employers do not want advanced M\&E. Research reported in this paper will address this alleged obstacle and show that this too can be averted - albeit with a change in approach.

Review of academic and professional literature indicates that a vast amount of knowledge and advice have been disseminated over the past 50 plus years and that identified obstacles to $\mathrm{M} \& \mathrm{E}$ have been largely addressed. The dichotomy illustrated by the lack of application in spite of the extensive body of theories, models and methods, suggests that there is something more going on than recognized in the literature to date. This concern spurred the research reported in this paper and led to the alternative approach and model presented.

\section{Methodology}

This conceptual paper is based on three concurrent stages of qualitative research. First, it is substantially informed by critical analysis of scholarly literature on measurement and evaluation, as well as professional literature published by industry institutes and associations such as Institute for Public Relations (IPR), national PR bodies in several countries such as the Public Relations Society of America (PRSA), the Chartered Institute for Public Relations (CIPR), the Public Relations Institute of Australia (PRIA), and the International Association for Measurement and Evaluation of Communication (AMEC). While it is traditional in scholarly papers and articles to focus on academic literature, the intersection of scholarly and professional literature provides a useful site at which to examine theory-practice alignment and/or gaps and identify obstacles encountered or perceived by practitioners in applying theories and models. A full comparative analysis of the two fields of literature was not undertaken, but a substantial body of discussion comprised of more than 250 journal articles, book chapters, professional articles and reports published over a 37-year period was examined to inform a rethinking of measurement and evaluation.

Second, this study included a review of 30 measurement and evaluation reports on PR and corporate communication produced for organizations. These comprised a convenience sample, based on reports that were available to the researcher ${ }^{1}$, but they were all reports of 
formal evaluation attempts of substantial campaigns or programs. Furthermore, they were broadly representative, as the reports were produced by or for a mix of major corporations, government agencies, international PR consultancies, and/or specialist measurement and evaluation service providers, and all were produced since 2005 - most since 2010 - so they reflect contemporary practice.

Third, this analysis drew on observations and ongoing 'conversations' with senior management on the 'employer/client side' conducted as ethnographic research over several years while working as an independent adviser ${ }^{2}$ on measurement and evaluation. While conducted semi-formally, rather than as formal interviews, this ethnographic component afforded an 'insider' perspective based on observation, conversations and interpretation during an extended period of field work. Tedlock notes that ethnographers "live in" a group under study for an extended period of time which she cites as "two years ideally" (2008, p. 151). This stage afforded direct access to CEOs, heads of marketing, and heads of communication employing external agencies in six organizations. Anonymity was provided to senior managers participating, but it can be disclosed that all worked with major national or international companies or organizations.

The literature review, analysis of M\&E reports and ethnographic observations and conversations were conducted over a period of more than three years in total, which also afforded time for applying reflectivity. In a qualitative context this is considered an advantage, as it allowed considerable opportunity for 'mulling over' the data. Significant conclusions emerged from reflection, which were not apparent in initial analysis of the literature or M\&E reports. Triangulation of the three data sets and reflection yielded the following findings.

\section{Limitations}

The qualitative nature of this research means that conclusions and findings are not generalizable, and some limitations resulting from the convenience sample of M\&E reports is acknowledged. Hence, the discussion, conclusions and recommendations are presented as a conceptual paper and further empirical testing of the proposed approach and models presented here is necessary. However, the concepts advanced have been shared and discussed with scholars and practitioners at conferences including the 2014 International Summit on Measurement and agreed to be worthy of broader debate and further research.

\section{Findings - Three hidden obstacles to overcome}

This qualitative research identified three obstacles to effective measurement and evaluation beyond those most extensively discussed in the literature. One of these has been noted by other researchers, although not examined in detail, while two others do not appear in a search of M\&E scholarly and professional discussion. These are briefly explained and then an approach and model to overcome them is proposed.

\section{Victims of the 'Enlightenment'}

A substantial obstacle that becomes evident in examining academic literature and reviewing $M \& E$ reports is the focus on science as the primary source of knowledge, a tendency that is buried deep in the belief systems and psyche of Western societies as a result of the Renaissance and the so-called 'Enlightenment' that laid the foundation for the industrial revolution and modernism. This results in an overwhelming use of quantitative methodology, which dominates the research landscape generally (Newman and Benz, 1998) and is influential in the dominant paradigm of PR (L'Etang, 2008, pp. 12, 249) as well corporate and marketing communication (Damon and Holloway, 2005). As L'Etang notes, PR has been 
promoted as a 'science' (2008 p. 249), suggesting generalizable truths and numerical precision are attainable and able to explain its function and effects. Indicative of this epistemological and methodological bias is the positioning statement of the major PR industry research organization, the Institute for Public Relations (IPR), which commits the institute to "the science beneath the art", clearly prioritizing science over the humanities.

As is well known, science and 'the scientific method' of research involve (1) the collection of empirical data and evidence using systematic quantitative methodology, and (2) analysis using deduction and logical rational reasoning. The language of quantitative research, the primary tools of which are derived from mathematics, is numbers representing counts, percentages, levels, degrees, weights, variances, and other factors.

Social science, while being concerned with human society and social issues, followed the scientific approach of natural science in its search for legitimacy and credibility in a modernist world. Early psychology and sociology relied heavily on quantitative data such as demographics and measures from scientific experiments to try to understand, influence and even control how humans think and behave. While the positivism of science and early social science has softened, modernist and late modern societies have continued to seek what political scientist Stephen Coleman calls the "seemingly unassailable aura of scientificity" (2013, p. 29) through classification, compilation and quantification using numbers.

Few if anyone would deny that science has brought substantial benefits to humankind. However, a corollary of the rise and celebration of scientific and social scientific knowledge has been a lessened focus on the third major approach to scholarship and knowledge creation - the humanistic perspective (Littlejohn and Foss, 2008). While acknowledging that numbers have "a rigor and logic" about them, John Durham Peters says that numbers have "a serene indifference to the world of human things" (Peters, 2001, p. 435). What Coleman, Peters and many other contemporary critics of modernism, positivism and behaviourism in the social sciences are challenging are (1) the reductionist processes of science which limit knowledge to certain types of observable data; (2) the notion of commensurability, a belief that diverse qualities can be measured by a common standard and reduced to a metric; and (3) the underpinning claim of the scientific method to objectivity achieved through detachment (Coleman, 2013, p. 29). As well as being reductionist, scientific research is purportedly conducted from a dispassionate perspective, detached from all human subjectivity and emotion. Therein lay its greatest limitation as a method for studying human communication.

As the extensive literature on human communication, public relations, and related fields shows, key outtakes and outcomes of communication and interaction include:

- $\quad$ Perceptions, such as reputation and brand attributes;

- Attitudes, such as goodwill, support, or intention to buy;

- Opinion, which involves attitudes but is often publicly expressed, whereas attitudes may remain latent;

- $\quad$ Trust;

- Engagement;

- Loyalty;

- Relationships; and

- Behaviour, such as buying, joining, voting, getting fit, advocacy in relation to a product, service or cause, and so on. 
Even a cursory review shows that most of these outtakes, outflows and outcomes are human interpretations and feelings, not independently and objectively observable phenomena. Even observable behaviours are heavily influenced by hermeneutics and affective as well as cognitive processing. That is to say, interpretations and feelings are based on emotion as well as rational logical reasoning. They are subjective, not objective. They are socially, culturally and contextually constructed, not scientific facts. They are infinitely variable and diverse, not stable phenomena. They are humanistic, not scientific. As such, they do not yield easily to numerical quantification and are simplistically represented in arbitrary scales and ratings.

As a number of scholars have noted, researchers and practitioners need to challenge the dominant quantitative paradigm and liberate PR and corporate communication from the straightjacket of positivist science to allow their true value to be revealed by complementing and supplementing quantitative research with insightful qualitative methods.

\section{The conflation of measurement and evaluation}

A second critically observed barrier to demonstrating the outcomes and value of PR and corporate communication is that 'measurement and evaluation' are widely spoken in the same breath and seen as conjoint and even concurrent processes - or even the same thing. For example, while making valuable contributions to the field, many of the texts cited in the literature review refer to both measurement and evaluation and do not clearly distinguish the two processes (e.g., Baskin et al., 2010; Likely and Watson, 2013; Michaelson and Stacks, 2011; Watson, 2012). Professional texts likewise fuse the two processes together (e.g., McCoy and Hargie, 2012). Watson and Noble $(2007,2014)$ are among the few to specifically define evaluation as distinct from measurement (e.g., 2014, pp. 17-19) and they point out significant inconsistency in the literature as well as noting that, like research methods, understanding of evaluation "is firmly rooted in social scientific research methods" (p. 17). However, notwithstanding their recognition of the importance of evaluation - not only measurement - models and methods presented under 'Evaluation and communication psychology' (Chapter 2) and 'Evaluating structures and processes' (Chapter 5) focus primarily on measurement techniques and methods (i.e., research) and do not adequately explain evaluation.

Other PR and corporate communication texts use the title 'research and evaluation' (e.g., Cornelissen, 2011, p.124; van Ruler, A. Verčič and D. Verčič, 2008), or simply 'evaluation' (e.g., Cutlip, Center and Broom, 2009; Wilcox and Cameron, 2010), but similarly focus mainly on measurement/research methods and metrics. Watson's late 1990s conclusion that there is "considerable confusion" about what constitutes evaluation remains true today (1997, p. 284) and the conflation of evaluation with measurement at a conceptual and practical level is problematic.

While supporting Watson and Noble's (2014) rejection of summative notions of evaluation i.e., that it is something done at the end of a program - and supporting their and others' view that evaluation should be linked to formative processes of planning, evaluation nevertheless has distinct qualities that are quite different to measurement and research. Whereas measurement, which literally means taking measures, is a two-stage research process involving data and data analysis, both the Oxford and Merriam-Webster dictionaries define evaluation as "to judge" or "making a judgement" about the value of something (MerriamWebster, 2014b; Oxford Dictionaries, 2014b).

Value is a perception. While it may be guided by various metrics, such as Key Performance Indicators (KPIs), scorecards or dashboards, value is ultimately a human judgement made from a perspective, such as that of organization management or a stakeholder. Researchers 
and practitioners developing and propagating metrics that claim to show the value of PR and corporate communication will do well to bear in mind Murray and White's interviews with "chief executives and chairmen" of major organizations which found that most "intuitively" valued PR (2005, p. 4). Grunig et al.'s (2002) compensating variation evaluations were also estimates based on the perceptions of CEOs gleaned from interviews. The significance of unconflating measurement and evaluation, along with the importance of qualitative research, will be further illustrated in discussing an alternate approach in the following section. But before that, one further obstacle compounds the M\&E deadlock and informs a new approach.

\section{Looking backwards}

Measurement and evaluation, often conflated and conducted concurrently, or even seen as the same process, are typically implemented as shown in Figure 1. Early findings from measurement are used for fine-tuning a program or campaign, and evaluation is undertaken primarily for reporting and performance management. In this approach, measurement and evaluation are focussed on looking backwards, and discussions with employers indicate that this is one of the most serious obstacles to successful implementation of measurement and, in particular, evaluation.

Findings primarily used for reporting past activities

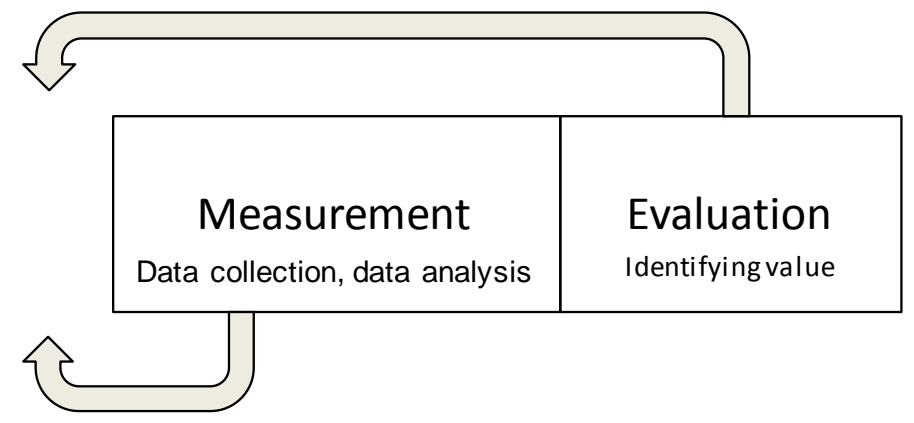

Early findings used to fine-tune campaign

Figure 1. Traditional M\&E approaches which blur and conflate measurement and evaluation.

Recognition of this obstacle helps explain the troubling contradiction in the M\&E debate that, despite management rhetoric in relation to accountability and demonstration of results, practitioners report that employers often do not want rigorous measurement and evaluation, or are not prepared to pay for it. As noted Baskin et al. (2010), many users of PR feel that they have sufficient information about what was done in the past. Others feel that 'what's done is done' - the past cannot be changed, so why dwell on it? Discussions with senior management conducted as part of this study found further evidence that employers do not want to pay for what they feel they already know (e.g., intuitively or anecdotally) and what cannot be changed in most cases. Conversely, they indicate that they are more likely to pay for what they don't know and what can change the future. Without prompting, several made the point that their primary focus was the future and challenged researchers and practitioners to “tell me what I don't know". Some senior management also perceives current measurement and evaluation practices as little more than self-justification and post-hoc rationalization by $\mathrm{PR}$ and communication practitioners.

A backwards looking focus was confirmed in analysis of M\&E reports. Only two of the reports examined contained a section discussing how findings of measurement could beneficially inform future strategy. All focussed primarily on presenting metrics in relation to past activities and these were overwhelmingly output metrics, such as volume of media 
articles; impressions, number of messages disseminated, audience reach, and volume of social media 'follows', 'likes' and 'shares'. While this sample was small, the findings reflect studies of M\&E practices reported by Wright et al. (2009), Michaelson and Stacks (2011), and others.

Based on the findings of critical analysis informed by the literature, M\&E reports studied, ethnography, and considered reflection, the following alternative approach and model for measurement and evaluation are proposed for discussion and further research.

\section{A new approach and model for measurement and evaluation}

\section{Measurement}

As noted extensively in the literature, the first stage of measurement and evaluation involves research, incorporating data collection and data analysis to provide metrics and analytics (meaningful patterns of data). The first element of a new approach to M\&E, as discussed previously, is that it should in most cases include qualitative as well as quantitative research.

\section{Analysis}

The second key characteristic of a new approach and model is designed to address two things that limit with the M\&E approach symbolized in Figure 1. When evaluation is undertaken as part of, or immediately after measurement, it is limited and narrow in terms of the data analyzed. It is usually focussed exclusively on endogenous data - the data collected in the specific measurement process undertaken by the organization and does not consider exogenous data that may be available. Instead of fusing evaluation with measurement processes, a new approach outlined in Figure 2 proposes two additional stages inserted between measurement and evaluation to produce the MAIE model.

The first of these additional stages is in-depth analysis that not only considers endogenous data, but looks beyond bespoke metrics and analytics to consider other information sources that can be used to triangulate and contextualize measurement metrics such as published research literature, databases including data mining to access publicly available 'Big Data' when appropriate, case studies, historical records, and theories and models - a number of which have been noted in the literature reviewed. This provides (1) a deeper, richer data pool and (2) a focussed process from which to produce findings. Rather than relying only on analysis of measurement data (i.e., metrics collected), this stage should be expanded to involve intensive analysis deploying techniques of critical analysis as described in academic literature, but also can include market analysis, competitor analysis, business analysis, and other contextual analysis drawing on the additional exogenous data accessed.

\section{Insights}

This deep analysis is proposed for two reasons. First, even before evaluation is attempted, analysis informed by measurement and other data is designed to identify insights that can inform future business or organization strategy - the third stage of this model. Rather than simply reporting past achievements, insights are forward-looking, creating potential for value adding initiatives by the organization, whether these create value through increases (such as in sales, reputation, or employee loyalty) or reductions (such as in costs or risk). Whereas traditional evaluation findings are mostly descriptive, insights involve inferences, predictions, suggestions, and recommendations. Insights might include, for example, identification of a gap left by competitors, an opportunity to seize thought-leadership on an emerging issue, a likely legislative initiative based on patterns of political comment, or a mood swing among stakeholders that can be productively addressed at an early stage. The MAIE model further materializes and operationalizes M\&E as part of an integrated formative-summative process 
as advocated by Broom and Dozier (1990) and Watson and Noble (2007, 2014), rather than a separate post-hoc stage of research.

This forward-looking approach designed to provide insights that contribute to future business or organization strategy and outcomes, as well as inform future PR and communication strategy and performance management, also helps bridge the gap between PR/corporate communication and organizational outcomes, which several studies have identified as a further challenge or obstacle confronting practitioners (e.g., Zerfass et al., 2012). Rather than trying to retrospectively link PR to business or organizational outcomes, which can be seen as post hoc rationalization, this approach produces positive contributions to the future success of the organization.

Inform strategic planning of next stage

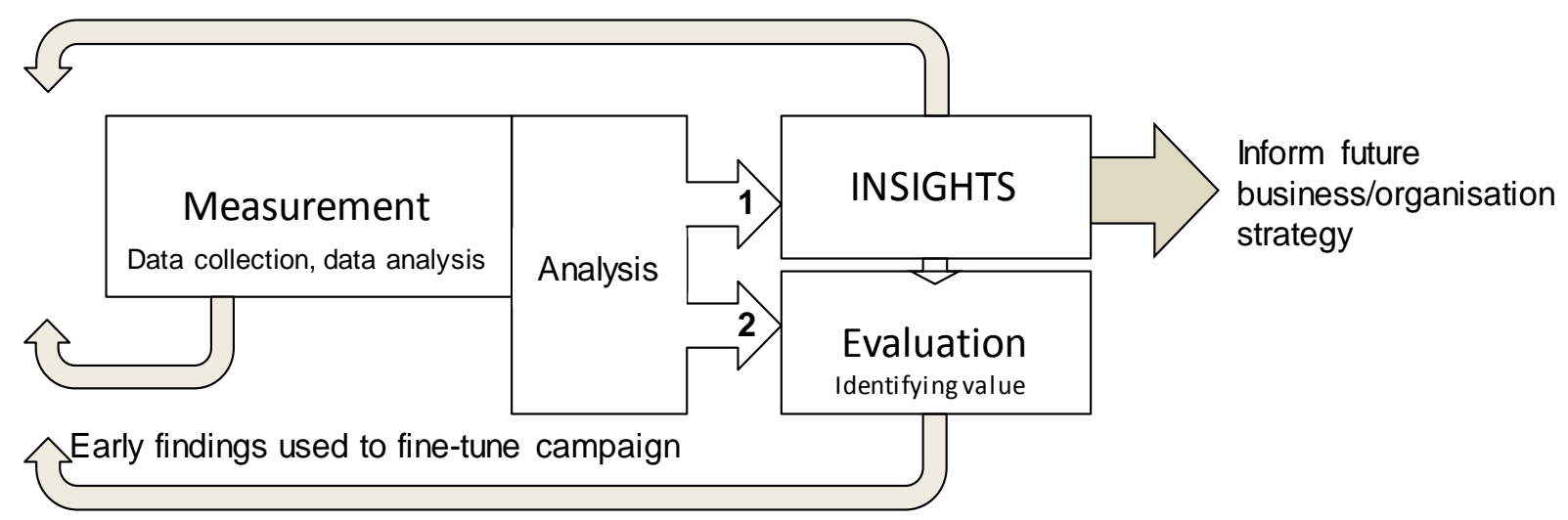

Reporting and performance management and review

Figure 2. The MAIE model of measurement and evaluation.

Producing insights rather than descriptive retrospective reports adds a further level of complexity, which is already seen as an obstacle by some practitioners (ICCO, 2013b). However, increasing research knowledge among practitioners, already identified as a key step to break the deadlock, could include familiarization with techniques such as triangulation of multiple data sets, comparative analysis (Frey et al., 2000), team analysis such as using multiple coders for text and content analysis (Neuendorf, 2002), data reduction and display (Miles and Huberman, 1994); reflectivity (Ben-Ari and Enosh, 2011), and other sense-making techniques.

\section{Evaluation}

Finally, as a fourth stage after measurement and intensive analysis to produce and present insights, evaluation can be undertaken in a productive way. However, again the approach suggested in the MAIE model is different to traditional practices. Rather than practitioners undertaking evaluation or outsourcing it to a service provider, or conflating it with measurement, it is posited as a collaborative process with management and stakeholders and it must inevitably involve qualitative assessments, given that value is perception. Methods such as compensating variation proposed by Ehling (1992) more than 20 years ago and expounded by Grunig et al. (2002) more than a decade ago - i.e., simply asking stakeholders what value they see resulting from certain activities - can be relevant and informative in this context.

The effect on evaluation undertaken at this stage should be obvious. Evaluation undertaken post insights is able to capture the value-add provided to management in insights and is 
therefore likely to reflect a much higher level of appreciation and perceived value among internal stakeholders than retrospective reports. Similarly, insights which recognize external stakeholders' perspectives and lead to organization actions to improve communication and relationships are likely to lead to increased value in the eyes of external stakeholders.

While gaining management support is a key focus of PR measurement and evaluation, consideration of both internal and external stakeholders is important, noting that PR Excellence theory proposes that evaluation should identify the value of PR at program, departmental, organizational and societal levels (Grunig et al., 2002; Grunig et al., 2006). The MAIE model particularly focusses on the two highest levels, which is important as many M\&E approaches focus on program and departmental reporting and much still remains to be done at the organizational and societal levels, as noted by Likely and Watson (2013).

\section{Conclusions}

This analysis has shown that strategies to overcome commonly cited obstacles to researchbased measurement and evaluation are available, but that three further more fundamental obstacles stand in the way of M\&E implementation: (1) over-reliance on quantitative research and a lack of qualitative research; (2) a conflation of measurement and evaluation which fails to recognize their distinctly different processes; and (3) a backwards looking approach which is seen by management as of marginal value, or self-justification and rationalization by practitioners.

To address these, a new approach and model for measurement and evaluation comprised of four key elements is proposed as a contribution to debate. This utilizes qualitative as well as quantitative research and adds to the process a stage of in-depth analysis based on exogenous as well as endogenous data to produce insights that inform future organizational strategy ideally for the mutual benefit of the organization and stakeholders. Finally, evaluation is undertaken collaboratively with management and stakeholders, recognizing value is a perception, hence utilizing qualitative interpretative data and feedback, as well as 'hard' (i.e., scientific) data that may be available.

\section{References}

Baskin, O. Hahn, J. Seaman, S. and Reines, D. (2010), "Perceived effectiveness and implementation of public relations measurement and evaluation tools among European providers and consumers of PR services”, Public Relations Review, Vol. 36 No. 2, pp. 105-11.

Ben-Ari, A. and Enosh, G. (2011). "Processes of reflectivity: Knowledge construction in qualitative research”, Qualitative Social Work, Vol. 10 No. 2, pp. 152-71, doi: 10.1177/1473325010369024.

Broom, G. and Dozier, D. (1983), “An overview: Evaluation research in public relations”, Public Relations Quarterly, No. 28, No. 3, pp. 5-9.

Broom, G. and Dozier, D. (1990), Using Research in Public Relations: Applications to Program Management, Prentice-Hall, Englewood Cliffs, NJ.

CIPR (Chartered Institute for Public Relations) 2011, "Research, planning and measurement toolkit”, available at http://www.cipr.co.uk/sites/default/files/Non-member\%20excerpt\%202_0.pdf (accessed 14 June 2014).

Coleman, S. (2013), How Voters Feel, Cambridge University Press, New York, NY.

Commission on Public Relations Education (2012), "Educating for complexity: Standards for a Masters degree in public relations”, October, available at http://www.commpred.org (accessed 25 March 2014).

Cornelissen, J. (2011), Corporate Communication: A Guide to Theory and Practice, London, UK, Sage. 
Cutler, A. (2004), "Methodical failure: The use of case study method by public relations researchers", Public Relations Review, Vol. 30 No. 3, pp. 365-75.

Cutlip, S. and Center, A. (1952). Effective Public Relations, Prentice-Hall, Englewood Cliffs, NJ.

Cutlip, M. Center, A. and Broom, G. (1985), Effective Public Relations, $6^{\text {th }}$ edn, Prentice Hall, Englewood Cliffs, NJ.

Cutlip, M. Center, A. and Broom, G. (2009), Effective Public Relations, $10^{\text {th }}$ edn, Prentice Hall, Upper Saddle River, NJ.

Damon, C. and Holloway, I. (2005), Qualitative Research Methods in Public Relations and Marketing Communications, Routledge, London, UK and New York, NY.

Dozier, D. (1984). "Program evaluation and the roles of practitioners”, Public Relations Review, Vol. 10 Vol. 2, pp. 13-21.

Dozier, D. (1985), "Planning and evaluation in public relations practice”, Public Relations Review, Vol. 11 No. 2, pp. 17-26.

Ehling, W. (1992), "Estimating the value of public relations and communication to an organization", in Grunig, J. (Ed.), Excellence in Public Relations and Communication Management, Lawrence Erlbaum Associates, Hillsdale, NJ, pp. 617-38.

Fairchild, M. (2001), "The IPR Toolkit: Planning, research and evaluation for public relations success”, Institute of Public Relations, London, UK.

Frey, L. Botan, C. and Kreps, G. (2000), Investigating Communication: An Introduction to Research Methods, Allyn \& Bacon, Needham Heights, MA.

Gregory, A. and Watson, T. (2008), "Defining the gap between research and practice in public relations programme evaluation - towards a new research agenda, Journal of Marketing Communications, Vol. 24 No. 5, pp. 337-50.

Gregory, A. and White, T. (2008), "Introducing the Chartered Institute of Public Relations initiative", in van Ruler, B. Verčič, A. and Verčič, D. (Eds), Public Relations Metrics: Research and Evaluation, Routledge, New York, NY, pp. 307-17.

Grunig, J. (1979), “The status of public relations research”, Public Relations Quarterly, Vol. 20, No. 1, pp. 5-8.

Grunig, J. (1983), “Basic research provides knowledge that makes evaluation possible”, Public Relations Quarterly, Vol. 28 No. 3, pp. 28-32.

Grunig, J. (2014), “Thought leaders in PR measurement”, Communicationcontrolling.de, available at http://www.communicationcontrolling.de/en/resources/interviews/thought-leaders.html (accessed 25 March 2014).

Grunig, J. Grunig, L. and Dozier, D. (2006), “The excellence theory”, in C. Botan and V. Hazelton (Eds), Public Relations Theory II, Lawrence Erlbaum, Mahwah, NJ, pp. 21-62.

Grunig, L. Grunig, J. and Dozier, D. (2002), Excellent Organizations and Effective Organizations: A Study of Communication Management in Three Countries, Lawrence Erlbaum, Mahwah, NJ.

Grunig, J. and Hunt, T. (1984), Managing Public Relations, Holt, Rinehart \& Winston, Orlando, FL.

Guth, D. and Marsh, C. (2007), Public Relations: A Values-driven Approach (3rd ed.), Pearson Education, Boston, MA.

Hallahan, K. (1993), “The paradigm struggle and public relations practice”, Public Relations Review, Vol. 19 No. 2, pp. 197-205.

ICCO (International Communications Consultancy Organization) (2013a), "ICCO world report”, available at http://www.iccopr.com/knowledge-base/Worldreports.aspx (accessed 26 March 2014).

ICCO (International Communications Consultancy Organization) (2013b), "ICCO trends barometer for Q3 2013”, Association for Measurement and Evaluation, available at http://amecorg.com/2013/03/survey-reports-measurement-never-more-important (accessed 27 March 2014).

IPRA (International Public Relations Association). (1994), "Public relations evaluation: Professional accountability”, Gold Paper No. 11. Geneva, Switzerland.

Lamme, M. and Russell, K. (2010), "Removing the spin: Towards a new theory of public relations history”, Journalism and Communication Monographs, Vol. 11 No. 4, pp. 281-362.

L’Etang, J. (2008), Public Relations: Concepts, Practice and Critique, Sage, London and Thousand Oaks, CA.

Likely, F. (2012), "Principles for the use of return on investment (ROI), Benefit-cost ration (BCR) and cost-effectiveness analysis (CEA) financial metrics in a public relations/communication 
(PR/C) department”, paper presented to the 15th International Public Relations Research Conference, Miami, FL, March.

Likely, F. and Watson, T. (2013), "Measuring the edifice: Public relations measurement and evaluation practice over the course of 40 years", in Sriramesh, K. Zerfass, A. and Kim, J. (Eds), Public Relations and Communication Management: Current Trends and Emerging Topics, Routledge, New York, pp. 143-62.

Lindenmann, W. (1979), “The missing link in public relations research”, Public Relations Review, Vol. 5, No. 1, pp. 26-36.

Lindenmann, W. (1980), “Hunches no longer suffice”, Public Relations Journal, Vol. 36, No. 6, pp. 9-13.

Lindenmann. W. (1993), “An 'effectiveness yardstick' to measure public relations success”, $P R$ Quarterly, Vol. 38 No. 1, pp. 7-9.

Lindenmann, W. (2001), “Research doesn't have to put you in the poorhouse”, Institute for Public Relations, Gainesville, FL, available at http://www.instituteforpr.org/topics/research-savings (accessed 26 March 2014).

Littlejohn, S. and Foss, K. (2008). Theories of Human Communication, $9^{\text {th }}$ edn, Thomson-Wadsworth, Belmont, CA.

Macnamara, J. (1992), “Evaluation: The Achilles heel of the public relations profession”, International Public Relations Review, Vol. 15 No. 4, pp. 17-31.

Macnamara, J. (1999), "Research in public relations: A review of the use of evaluation and formative research”, Asia Pacific Public Relations Review, Vol. 1 No. 2, pp. 107-33.

Macnamara, J. (2002), "Research and evaluation”, in Tymson, C. and Lazar, P. (Eds), The New Australian and New Zealand Public Relations Manual, Tymson Communications, Sydney, pp. 100-134.

Macnamara, J. (2012), Public Relations Theories, Practices, Critiques, Pearson, Sydney, NSW.

Macnamara, J. (2013), "The toe bone to the head bone logic model: An approach to connect PR and corporate communication to organization and business outcomes”, Association for Measurement and Evaluation of Communication, London, UK, available at http://amecorg.com/2013/05/toebone-to-the-head-bone-logic-model (accessed 25 March 2014).

Macnamara J. (2014), “Emerging international standards for measurement and evaluation of public relations: A critical analysis”, Public Relations Inquiry, Vol. 3 No. 1, pp. 7-28.

Marklein, T. and Paine, K. (2012), "The march to standards", presentation to the $4^{\text {th }}$ European Summit on Measurement, Dublin, Ireland, June, available at http://amecorg.com/downloads/dublin2012/The-March-to-Social-Standards-Tim-Marklein-andKatie-Paine.pdf (accessed 10 March 2014).

McCoy, M. and Hargie, O. (2012), "Measurement and evaluation”, in Theaker, A. (Ed.), The Public Relations Handbook, $4^{\text {th }}$ edn, Routledge, Abingdon, Oxon. UK, pp. 195-218.

Merriam-Webster (2014b), "Evaluation”, available at http://www.merriamwebster.com/dictionary/evaluate (accessed 26 March 2014).

Michaelson, D. and Stacks, D. (2011), "Standardization in public relations measurement and evaluation”, Public Relations Journal, Vol. 5, No. 2, pp. 1-22.

Miles, M. and Huberman, M. (1994), Qualitative Data Analysis, Sage, Thousand Oaks, CA.

Murray, K. and White, J. (2005) “CEOs' views on reputation management”, Journal of Communication Management, Vol. 9 No. 4, pp. 348-58.

Newman, I. and Benz, C. (1998), Qualitative-quantitative Research Methodology: Exploring the Interactive Continuum, Southern Illinois University, Carbondale, IL.

Neuendorf, K. (2002), The Content Analysis Guidebook, Sage, Thousand Oaks, CA.

Noble, P. and Watson, T. (1999), "Applying a unified public relations evaluation model in a European context”, paper presented to the Transnational Communication in Europe: Practice and Research Congress, Berlin, Germany.

Oxford Dictionaries. (2014b), "Evaluation”, available at http://www.oxforddictionaries.com/definition/english/evaluation (accessed 26 March 2014).

Pavlik, J. (1987), Public Relations: What Research Tells Us, Sage, Newbury Park, CA.

Peters, J. (2001), “The only proper scale of representation: The politics of statistics and stories”, Political Communication, Vol. 18 No. 4, pp. 433-50. 
PRSA (Public Relations Society of America) (2014), “Measurement resources”, available at http://www.prsa.org/intelligence/businesscase/measurementresources (accessed 14 June 2014).

Ragan/NASDAQ OMX Corporate Solutions (2013), "PR Measurement”. Chicago, IL. Available at http://bit.ly/PRMeasureWPPR (accessed 10 March 2014).

Skelley, L. and Ziviani, M. (2012), "Measuring PR performance across borders - how a global programme works", in 'PR Professionals Definitive Guide to Measurement, Association for Measurement and Evaluation of Communication, London, UK, available at http://prguidetomeasurement.org/wp-content/uploads/2013/04/Chapter-5-Laura-Skelley-MichaelZiviani.pdf (accessed 25 March 2014).

Tedlock, B. (2008), "The observation of participation and the emergence of public ethnography”, in Denzin, N. and Lincoln, Y. (Eds), Strategies of Qualitative Inquiry, $3^{\text {rd }}$ edn, Sage, Thousand Oaks, CA, pp. 151-71.

van Ruler, B. Verčič, A. and Verčič, D. (Eds) (2008), Public Relations Metrics: Research and Evaluation, Routledge, New York, NY.

VanSlyke Turk, J. (Ed.) (2006), "The professional bond: Public relations education for the $21^{\text {st }}$ century”, Commission on Public Relations Education, available at http://www.commpred.org (accessed 25 March 2014).

Walker, G. (1997), "Public relations practitioners' use of research, measurement and evaluation”, Australian Journal of Communication, Vol. 24 No. 2, pp. 97-113.

Watson, T. (1997), "Measuring the success rate: Evaluating the PR process and PR programmes", in Kitchen, P. (Ed.), Public Relations Principles and Practice, International Thomson Business Press, London, UK, pp. 283-99.

Watson, T. (2008), "Public relations research priorities: A Delphi study", Journal of Communication Management, Vol. 12 No. 2, pp. 104-23.

Watson, T. (2012), “The evolution of public relations measurement and evaluation”, Public Relations Review, Vol. 38 No. 3, pp. 390-98.

Watson, T. and Noble, P. (2007), Evaluating Public Relations: A Best Practice Guide to Public Relations Planning, Research and Evaluation, $2^{\text {nd }}$ edn, Kogan Page, London and Philadelphia, PA.

Watson, T. and Noble, P. (2014), Evaluating Public Relations: A Best Practice Guide to Public Relations Planning, Research and Evaluation, $3^{\text {rd }}$ edn, Kogan Page, London and Philadelphia, PA.

Weiner, M. (2006), Unleashing the Power of PR: A Contrarians Guide to Marketing and Communication, John Wiley \& Sons, San Francisco, CA.

White, J. and Blamphin, J. (1994), Priorities for Research into Public Relations Practice in the United Kingdom, City University Business School and Rapier Marketing, London, UK.

Wilcox, D. and Cameron, G. (2010), Public Relations: Strategies and Tactics, $9^{\text {th }}$ edn, Allyn \& Bacon, Boston, MA.

Wright, D. and Hinson, M. (2012), "Examining how social and emerging media have been used in public relations between 2006 and 2012: A longitudinal analysis”, Public Relations Journal, Vol. 6 No. 4, pp. 1-40.

Wright, D. Gaunt, R. Leggetter, B. Daniels, M. and Zerfass, A. (2009), “Global survey of communications measurement 2009 - final report, Association for Measurement and Evaluation of Communication, London, UK, available at http://amecorg.com/wpcontent/uploads/2011/08/Global-Survey-Communications_Measurement-20091.pdf (accessed 10 March 2014).

Zerfass, A. (2010), “Assuring rationality and transparency in corporate communications. Theoretical foundations and empirical findings on communication controlling and communication performance management”, in Dodd, M. and Yamamura, K. (Eds), Ethical Issues for Public Relations Practice in a Multicultural World, $13^{\text {th }}$ International Public Relations Research Conference, Institute for Public Relations, Gainesville, FL, pp. 947-66 .

Zerfass, A. Verčič, D. Verhoeven, P. Moreno, A. and Tench, R. (2012), "European communication monitor 2012: Challenges and competencies for strategic communication”, Helios Media and EACD/EUPRERA, Brussels, Belgium. 


\section{Reference:}

Macnamara, J. (2015), “Overcoming the measurement and evaluation deadlock: A new approach and model”, Journal of Communication Management, vol. 19, no. 4, pp. 371-387. doi: 10.1108/JCOM-04-2014-0020

* Jim Macnamara PhD, FPRIA, FAMI, CPM, FAMEC is Professor of Public Communication at the University of Technology Sydney, a position he took up in 2007 after a 30-year professional career spanning journalism, public relations and media research. He is the author of 15 books including Public Relations Theories, Practices, Critiques published by Pearson Australia in 2012, The 21 $1^{\text {st }}$ Century Media (R)evolution: Emergent Communication Practices of which the second edition was published by Peter Lang, New York in 2013, and Journalism and PR: Unpacking 'Spin', Stereotypes and Media Myths to be published by Peter Lang, New York in 2014.

1 Many measurement and evaluation reports are confidential.

2 The author was an academic adviser and not associated with any M\&E service provider or consultancy. 